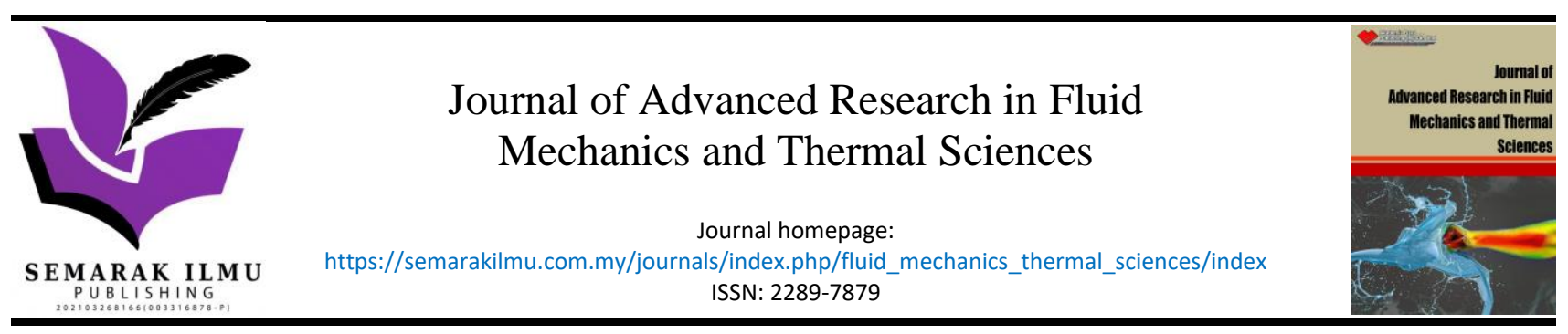

\title{
Metals and Alloys Additives as Enhancer for Rocket Propulsion: A Review
}

\author{
Izham Izzat Ismail ${ }^{1}$, Norhuda Hidayah Nordin ${ }^{2, *}$, Muhammad Hanafi Azami ${ }^{1}$, Nur Azam Abdullah ${ }^{1}$ \\ Department of Mechanical Engineering, International Islamic University Malaysia, Kuala Lumpur, Malaysia \\ Department of Manufacturing and Materials Engineering, International Islamic University Malaysia, Kuala Lumpur, Malaysia
}

\section{ARTICLE INFO}

\section{Article history:}

Received 14 August 2021

Received in revised form 25 October 2021

Accepted 3 November 2021

Available online 7 December 2021

\section{Keywords:}

Propellants; metal additives; metal catalyst; high entropy alloys

\section{ABSTRACT}

A rocket's engine usually uses fuel and oxygen as propellants to increase the rocket's projection during launch. Nowadays, metallic ingredients are commonly used in the rocket's operation to increase its performance. Metallic ingredients have a high energy density, flame temperature, and regression rate that are important factors in the propulsion process. There is a wide range of additives have been reported so far as catalysts for rocket propulsion. The studies show that the presence of metal additives improves the regression rate, specific impulse and combustion efficiency. Herein, the common energetic additives for rocket propulsion such as metal and light metals are reviewed. Besides the effect of these energetic particles on the regression behaviors of base (hybrid) fuel has been exclusively discussed. This paper also proposed a new alloy namely high entropy alloys (HEAs) as a new energetic additive that can potentially increase the performance of the rocket propellant system.

\section{Introduction}

The modern age of rockets began in (1903) when Konstantin Tsiolkovsky, suggested the concept of space exploration by rocket. He proposed that the usage of liquid propellants in the rockets can increase the range of thrust, reignition and reuse capability as well as throttlability [1]. Generally, a rocket usually uses fuel and oxygen as propellants for the rocket engine to enhance the projection during launching. The most common rocket components include pre-chamber, port grain, postchamber, and nozzle. The combustor is the location where the propellants are combined and detonated. The rocket's operating medium is the combustion product formed during combustion [2]. According to Newton's third law, many rocket engines use internal combustion engines to transform reaction mass from inside the vehicle into a high-speed projectile $[3,4]$.

The general principle of rocket propulsion is that it can happen in a variety of ways and can be categorized in various methods, such as the type of rocket engine and propellant used. Pure liquid or solid propellant has traditionally been used in chemical rockets for propulsion applications [5]. The two most common types of rocket engines are liquid and solid rockets. In a liquid rocket, the fluids which consist of the fuel and oxidizer are stored separately. In contrast to liquid rockets, the

\footnotetext{
* Corresponding author.

E-mail address: norhudahidayah@iium.edu.my
}

https://doi.org/10.37934/arfmts.89.2.19 
propellants in solid rockets are mixed and loaded into a rigid container. A hybrid rocket, on the other hand, combines solid fuel with a liquid or gas oxidizer $[3,6]$. It can be described as a rocket engine category in which the solid fuel is a polymer material and the oxidizer is a liquid or gaseous material. But the fuel and oxidizer components are stored in separate phases. A traditional hybrid rocket motor offers many advantages over liquid and solid rocket motors in terms of its safe handling, throttling, and environmental cleanliness [7]. The hybrid rocket motor also is highly suitable as the throttle-able rocket motor since it can be throttled easily by adjusting the oxidizer mass flow rate [8]. In comparison to the liquid propellant, only a single propellant feed system was needed thus these are light in weight. The number of options available in designing the fuel grain is also higher compared to the solid propellant rocket motor [9]. Figure 1 illustrates the difference between liquid, solid, and hybrid chemical configurations.

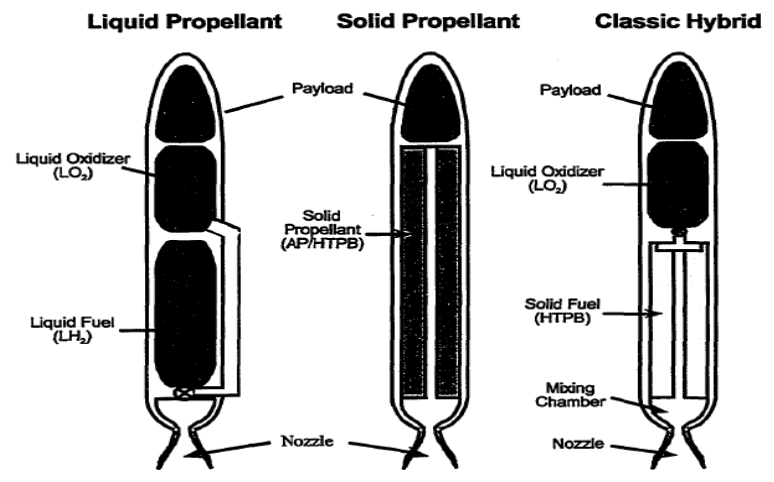

Fig. 1. The configurations of liquid, solid, and hybrid chemical propulsion concepts

The regression rate is regarded as the crucial parameter that has a first-order effect on the engine design and thus on the engine performance. In the context of non-premixed diffusion combustion, the fuel regression rate of a hybrid rocket engine is lower than a solid rocket engine [10]. The regression rate of the hybrid rocket motor can be calculated by using Eq. (1).

$\dot{r}=\frac{\dot{q}_{\text {wall }}}{\rho_{\text {fuel }} h_{v}}$

where the $\dot{q}_{\text {wall }}, \rho_{\text {fuel }}$, and $h_{v}$ represent the wall heat flux, density of fuel grain, and heat decomposition, respectively. As stated in rocket propulsion theory, thrust can be described as a propulsive force generated by transmitting a moment change to the exhaust combustion gases at the convergent-divergent nozzle at the divergence section. The hot combustion is produced from burning the propellant in the rocket engine's combustion chamber and the resulting burning gases can increase the speed and atmospheric pressure that flows into the nozzle which allows momentum to change. The momentum that has driven the rocket forward from the moment force shift known as thrust [9]. The rocket thrust can be calculated by using the following nozzle relations:

$T=\dot{m} U_{e}+\left(p_{e}-p_{0}\right) A_{e}$

where $\dot{m}, U_{e}, p_{e}, p_{0}$, and $A_{e}$ represent mass flow rate, exit velocity, exit pressure, ambient pressure, and nozzle exit area. The specific impulse also can be calculated using Eq. (3) to measure how effectively a rocket uses a propellant. 


$$
I_{s p}=\frac{T}{\dot{m} g}
$$

Additives are required to boost mechanical strength since pure paraffin fuels have low mechanical strength, making them unsuitable for practical applications. The form and quantity of additives need to be carefully selected to maintain the paraffin-based fuel's high regression rate and meet the mechanical strength requirement. Stearic acid (SA) and ethylene-vinyl acetate (EVA) are two additives that can effectively improve the mechanical strength of solid fuel [11]. In terms of chemical concepts, adding solid additives such as metals and metal hydrides can enhance the overall regression rate and the performance of hybrid rocket fuels [12]. Aluminum is one of the most studied additives in solid fuel formulations since it has relatively high oxidation heat and easy ignition in the combustion chamber $[13,14]$. Other metal additives such as Magnesium (Mg) and carbon black (C) also increase the rate of fuel regression [15].

This paper investigates and reviews some energetic additives such as metals and light metal hydrides that have been reported as catalysts for rocket propulsion. The effect of these energetic particles on the regression behaviors of base (hybrid) fuel has been exclusively discussed. Besides this paper also proposed a new alloy namely high entropy alloys (HEAs) as a new energetic additive that can potentially increase the performance of the rocket propellant system. Finally, a conclusion is drawn towards the importance of energetic additives on hybrid fuel regression enhancement in rocket propulsion.

\section{Energetic Additives}

Nowadays, the operation of the rocket with the presence of metallic ingredients is widely used to increase performance. Metallic ingredients bring high energy density, flame temperature, and regression rate for the propulsion application. Quick ignition and short particle burn period can be achieved with high specific surface area additives, resulting in high conversion efficiency within a combustor's residence time. However, additional complexities can arise as a result of the addition of additives, such as a change in the optimal O/F during operation, changes in the fuel's mechanical and rheological properties.

\subsection{Aluminium}

Aluminum has previously been utilised to increase the regression rate and combustion temperature in hybrid rocket engines. In addition, because less oxidizer is required to burn a comparable volume of aluminized fuel grain compared to pure paraffin wax fuel grain, the oxidizerfuel ratio is lowered, allowing for the design of a more compact rocket. According to Stanford University research, a $40 \%$ aluminized paraffin wax/nitrous oxide propellant has a $25 \%$ higher rate of regression than plain paraffin wax [16]. Besides, due to its relatively high heat of oxidation, high density, and ease of ignition, aluminum is the most researched additive for solid fuel formulations. Micro-scale aluminum accelerates solid grain regression by releasing energy from metal oxidation and rising radiation heat fluxes from the diffusion flame zone to the fuel surface. As compared to their micro-particle equivalents, nano-particle additives have been shown to produce improved combustion efficiencies, enhanced heat transfer processes, and shorter ignition delay and burning times [17]. However, nano-additives have a higher cost, are more difficult to synthesize and process, and have a lower safety profile. In some studies, due to the high melting temperatures associated with the aluminum oxide that coats the aluminum surfaces, adding aluminum particles to the fuel grain does not significantly improve the regression rate. 
According to [18], it has been discovered that combining Paraffin with gaseous oxygen and HTPB with $\mathrm{G}_{\mathrm{ox}}$, which includes $5 \%$ aluminum, will increase the specific impulse. From the research that has been done by [19], it has been discovered that combining Paraffin with gaseous oxygen and HTPB, which includes $5 \%$ aluminum, will increase the vacuum specific impulse by $30 \%$. However, the addition of $2.5 \%$ had no synergistic effect with KNSu, resulting in decreased propellant efficiency. Total thrust was reduced by more than $27 \%$, while average thrust was reduced by more than $50 \%$. The presence of $7.5 \mathrm{wt} \% \mathrm{Al}$ wastes resulted in a further reduction in the evaluated parameters. This finding indicates that higher levels of residue absorption are not recommended. According to [20], which included 5 separate samples, raising the oxidizer flux increases the regression rate. Figure 2 shows that pure paraffin wax has the highest regression rate, while $20 \%$ aluminum loading has the lowest.

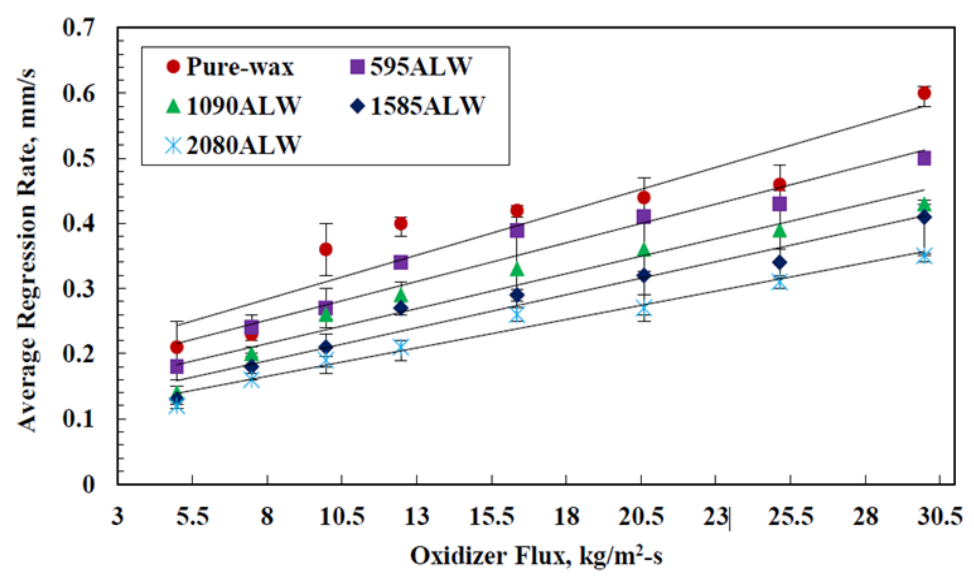

Fig. 2. Average regression rate trends for paraffin-wax and aluminized solid fuels [14]

It has been found that as the aluminum concentration in the wax increases, the regression rate decreases. This may be due to necessary heat transfer to the fuel surface is lost due to the agglomerates ejection, the aluminum particles tend to be expelled from the fuel surface and burn too far away to provide enough energy to improve the regression rate. As a result, a significant amount of aluminum particles was unable to combust efficiently on the burning surface, which was eventually reflected in a lower regression rate.

\subsection{Boron}

Boron is thought to improve regression because it has a higher volumetric heat release than aluminum, but its use is restricted due to its difficulty in the ignition, which can result in poor combustion efficiencies [13]. The addition of B to HTPB improved the output in terms of short ignition, combustion times, and heat release near the fuel surface. However, when these metallic powders/particles are mixed with pure Paraffin wax, they cause combustion instability, regression rate sensitivity over the combustion pressure, and oxide formation in the combustion products. Based on Figure 3, the addition of boron made the radial temperature distribution more uniform. In comparison to a pure HTPB fuel case, a $5 \%$ percent boron addition resulted in a $6.8 \%$ increase in Isp output, and a $10 \%$ percent boron addition resulted in a $13.7 \%$ increase [21]. 


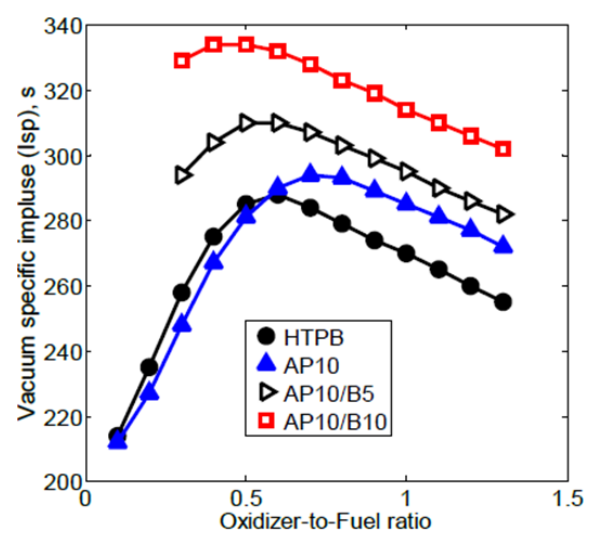

Fig. 3. Overall system vacuum Isp performance versus O/F ratio [15]

\subsection{Magnesium}

Most of the researchers also suggest Magnesium $(\mathrm{Mg})$ as a possible rocket propellant additive. Metal additives such as Magnesium (Mg) and carbon black (C) can significantly increase the rate of fuel regression in the HTPB fuel [22-24]. This is because Magnesium (Mg) has a high proclivity to react on the surface, thus improves heat feedback to the grain. This feature increases the diffusive heat signature thus promoting nucleation and disruptive burning of fuel. As a result, it improves fuel regression, which is aided by condensed phase heat release [12]. In another study, Magnesium (Mg) has been used as an additive in Paraffin wax (PW) fuels. Two types of Magnesium (Mg) powders of size $1 \mu \mathrm{m}$ and $100 \mu \mathrm{m}$ were used in the proportion of $15 \%$ by weight [25]. Table 1 below shows the results of the study. It can be observed that the regression rate deteriorates at lower oxidizer mass flux for smaller Magnesium (Mg) particles.

Table 1

Relative regression rate enhancement (\%) with respect to PW fuel [12]

\begin{tabular}{lll}
\hline Relative enhancement $(\%)$ & \multicolumn{2}{c}{ Oxidiser Mass Flux $\left(\mathrm{kg} / \mathrm{m}^{2} \mathrm{~s}\right)$} \\
\hline Particle size $(\mu \mathrm{m})$ & 100 & 335 \\
\hline 1.0 & $-47.6 \%$ & $163.2 \%$ \\
100 & $49.2 \%$ & $82.1 \%$ \\
\hline
\end{tabular}

To observe the HTPB/GOX regression rate performance, [22] used magnesium particles of size 10 $\mathrm{m}$ that were applied in a ratio of $15 \%$ to the fuel weight. Based on the research, there is a $15.5 \%$ increase in the relative regression rate [22]. According to [5], the development programmed for the Air Force's Sandpiper Target Missile was the first demonstration of hybrid motor firings with metal additives, and it involved combustion testing of PMMA fuel filled with several metallic powders burning in the MON-25 oxidizer. The results showed that the addition of a magnesium additive increased regression rates, and increasing loading $(5,10$, and $20 \%)$ which increased the regression rates even more but resulted in less effective combustion [26].

\subsection{Metal Hydrides}

The use of light metal hydrides as an enhanced additive for hybrid rocket propulsion has been the subject of extensive research. Magnesium hydride $(\mathrm{MgH} 2)$ is a good hydrogen source and could be used to store hydrogen. The emission of nascent hydrogen, as well as the combustion radiation of magnesium alloy, accelerates the rate of fuel regression when magnesium hydride $(\mathrm{MgH} 2)$ is 
employed. In addition to the heat of combustion, the release of hydrogen bubbles promotes grain pyrolysis. It has a higher thermal heat conductivity than base metal $(\mathrm{Mg})$, which simplifies ignition and combustion. Carmicno \& Sorge also studied the effects of $\mathrm{MgH} 2$ as additives on HTPB/GOX system [22]. After doping 5\% by weight of the HTPB fuel with $\mathrm{MgH} 2$ particles of size $47 \mathrm{~m}$, they observed regression behaviour. There was a $15.6 \%$ improvement in the relative regression rate.

Moreover, metal hydrides are a type of metal-based additive that can greatly increase the specific impulse of hybrid rocket propulsion systems. However, due to their high reactivity with water and humid air, metal hydrides are difficult to incorporate. Figure 4 shows the difference in impulse efficiency due to the addition of these additives.

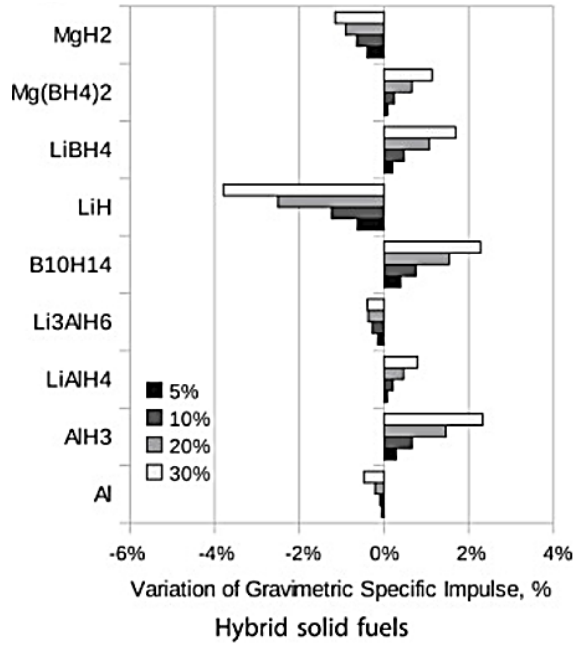

(a)

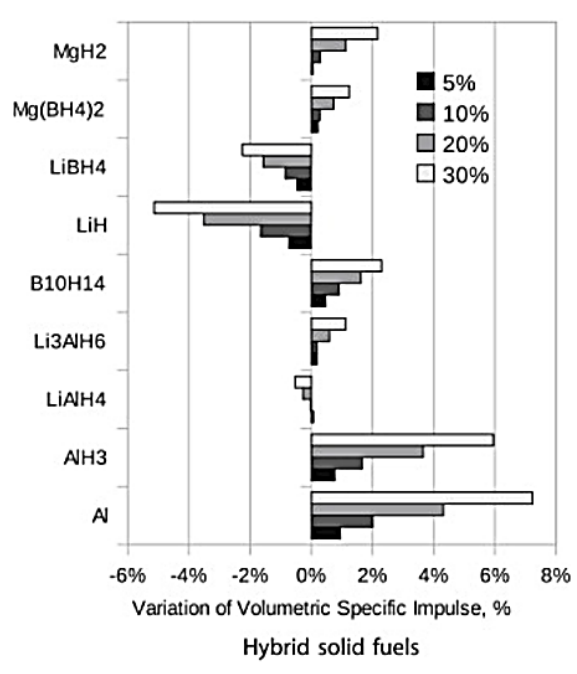

(b)

Fig. 4. (a) Gravimetric and (b) volumetric specific impulse performance variation with the inclusion of various metal hydrides in comparison to plain HTPB burning in oxygen [27]

These calculations revealed that among the metal hydrides studied, aluminum hydride (AlH3) has the greatest potential for improving specific impulse. Figure 5 illustrates that the addition of aluminum hydride (AlH3) improves the regression rate slightly more than magnesium hydride (MgH2).

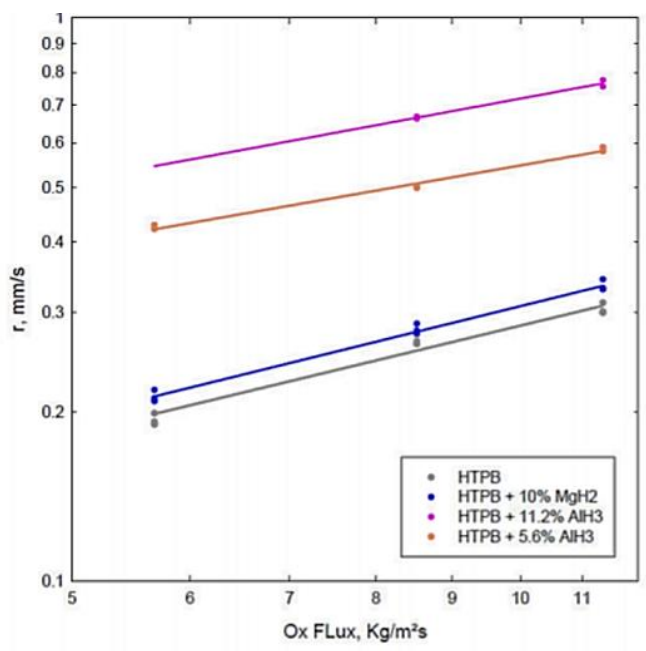

Fig. 5. Regression rate comparisons of fuel formulations containing $\mathrm{MgH} 2$ and AlH3 [28] 


\subsection{High Entropy Alloys (HEAs)}

Recently, high entropy alloys (HEAs) were found to have great potential as catalytic materials in catalyzing chemical transformation and energy conversion reactions [24,25]. HEAs are generally defined as solid solution alloy with five or more principal elements which comprise four core effects (high entropy, sluggish diffusion, lattice distortion, and cocktail effect). Several thermodynamics models such as Gibbs energy and mixing entropy are proposed to design the solid solubility of the HEAs. Despite their excellent mechanical properties, [29] claimed HEAs have better catalytic performance than conventional alloys due to high surface area and vital adsorption energy derived from the multi-elements in HEAs.

The enthusiasm behind studying multi element alloys for use as a catalytic agent comes directly from the essential near continuous distribution of adsorption energy [30], high specific surface area [29], and unusual atomic structure with significant lattice distortion and residual stress. HEAs can provide a surface with many unique binding site conditions, resulting in the near-range dispersal of associated adsorption energies. As a result, active sites with optimal properties will dominate catalytic activity within this distribution and provide the most vital catalyst sites. Moreover, HEAs also have inherent surface complexity. HEAs can provide a very large number of unique binding site environments, resulting in a near-continuous distribution of the associated adsorption energies and can be modified by alloying these adsorption energies and thus boosting catalytic activity compared to pure components [30]. This will provide an excellent increase in reaction rates. In addition, due to the varying atomic radius and geometrical configurations of different elements, the crystal lattice of HEAs can be modified over a certain distance. Moreover, their excellent ability to achieve high entropy alloys is due to unusual atomic structure with significant lattice distortion, the effect of chemical composition, residual stress, and high specific surface area [31]. Therefore, the stated reasons are considered to be plausible reasons for improving the combustion catalyst for advanced propellant formulations to improve their energetic performance. Besides, the nanoscale size of this alloy can enhance the burning rate of the propellants. The surface morphology and surface area will provide a molecular interaction with the propellent ingredients and desired electron affinity. This scenario will support the change of solid-state and gas-phase reaction mechanism between oxidizer and fuel. This will improve the reaction process in the flame zone thus enhancing the combustion efficiency of the rocket system [32].

\section{Conclusions}

The use of the energetic additive in hybrid propulsion has gained popularity within the scientific community and has a huge commercial potential. Compared to conventional systems, hybrid propulsion offers safety, reliability, and an environmentally friendly alternative. A hybrid rocket combines solid fuel and gaseous oxidizer along with energetic particles as additives. Through this paper, some energetic additives such as metals and light metal hydrides that have been reported as catalysts for rocket propulsion are discussed. Besides the effect of these energetic particles on the regression behaviors of base (hybrid) fuel also has been exclusively discussed. HEAs are seen as promising energetic metal additives than traditional alloys due to the high surface area and critical adsorption energy that is derived from the multi-elements in HEAs. Nanosized HEAs catalyst can be more attractive as it is expected to increase the burning rate thus improve the combustion efficiency of the propulsion system.

To date, numerous researches have been undertaken to identify the best catalyst or energetic additives for better performance of rocket propulsion. The nanoscale size of the catalyst is desired 
as it can increase the combustion characteristics, burning rate, the spatial distribution of energy released and combustion efficiency. However, the comprehensive studies on the development, characterizations and efficacy of the nanocatalyst metal and alloys are still low. Besides, the best synthesis method with good quality nanocatalyst is important to ensure the reproduction of the catalyst in the future for scaling up purposes.

\section{Acknowledgment}

This work was supported by the Ministry of Education Malaysia grant no (FRGS/1/2019/TK05/UIAM/03/3) and the International Islamic University Malaysia (IIUM).

\section{References}

[1] Burleson, D. "Konstantin Tsiolkovsky-The father of astronautics and rocket dynamics." In 40th AlAA Aerospace Sciences Meeting \& Exhibit, p. 312.

[2] Otkur, Murat. "Altitude Performance and Fuel Consumption Modelling of Aircraft Piston Engine Rotax 912 S/ULS." Journal of Advanced Research in Applied Sciences and Engineering Technology 23, no. 1 (2021): 18-25.

[3] Zhao, Bo, Nanjia Yu, Yufei Liu, Peng Zeng, and Jue Wang. "Unsteady simulation and experimental study of hydrogen peroxide throttleable catalyst hybrid rocket motor." Aerospace Science and Technology 76 (2018): 27-36. https://doi.org/10.1016/i.ast.2018.02.008

[4] Yacob, Noraishah Shafiqah, and Hassan Mohamed. "Investigation of Palm Oil Wastes Characteristics for Co-Firing with Coal." Journal of Advanced Research in Applied Sciences and Engineering Technology 23, no. 1 (2021): 34-42. https://doi.org/10.37934/arfmts.88.2.113

[5] Thomas, James C. "Mixed HTPB/Paraffin Fuels and Metallic Additives for Hybrid Rocket Applications." PhD diss., 2018.

[6] Ridhuan, Amir, Shahrul Azmir Osman, Mas Fawzi, Ahmad Jais Alimin, and Saliza Azlina Osman. "A Review of Comparative Study on The Effect of Hydroxyl Gas in Internal Combustion Engine (ICE) On Engine Performance and Exhaust Emission." Journal of Advanced Research in Fluid Mechanics and Thermal Sciences 87, no. 2 (2021): 1-16. https://doi.org/10.37934/arfmts.87.2.116

[7] Yousef, Muntaha A., and M. Keith Hudson. "Thermal study of the decomposition of HTPB hybrid rocket fuel in the presence of azo-tetrazolate-based high nitrogen content high energy materials." Journal of Thermal Analysis and Calorimetry 134, no. 3 (2018): 1785-1797. https://doi.org/10.1007/s10973-018-7490-6

[8] Cai, Guobiao, Yuanjun Zhang, Hui Tian, Pengfei Wang, and Nanjia Yu. "Effect of grain port length-diameter ratio on combustion performance in hybrid rocket motors." Acta Astronautica 128 (2016): 83-90. https://doi.org/10.1016/i.actaastro.2016.07.002

[9] Shrivastava, Aaditya. "Eco-Friendly Propellant for Hybrid Rocket Motor." In Proceedings of the International Conference on Modern Research in Aerospace Engineering, pp. 35-41. Springer, Singapore, 2018. https://doi.org/10.1007/978-981-10-5849-3 4

[10] Zhang, Shuai, Fan Hu, and Weihua Zhang. "Numerical investigation on the regression rate of hybrid rocket motor with star swirl fuel grain." Acta Astronautica 127 (2016): 384-393. https://doi.org/10.1016/j.actaastro.2016.06.017

[11] $\mathrm{Wu}, \mathrm{Yi}$, Xilong Yu, Xin Lin, Sen Li, Xiaolin Wei, Chuan Zhu, and Linlin Wu. "Experimental investigation of fuel composition and mix-enhancer effects on the performance of paraffin-based hybrid rocket motors." Aerospace Science and Technology 82 (2018): 620-627. https://doi.org/10.1016/i.ast.2018.09.026

[12] Akhter, Md Zishan, and M. A. Hassan. "Energetic Additives for Hybrid Rocket Propulsion-Review." In 2020 Advances in Science and Engineering Technology International Conferences (ASET), pp. 1-6. IEEE. https://doi.org/10.1109/ASET48392.2020.9118206

[13] Veale, Kirsty, Sarp Adali, Jean Pitot, and Michael Brooks. "A review of the performance and structural considerations of paraffin wax hybrid rocket fuels with additives." Acta Astronautica 141 (2017): 196-208. https://doi.org/10.1016/i.actaastro.2017.10.012

[14] Alfarawi, Suliman SS, Azeldin El-sawi, and Hossin Omar. "Exploring Discontinuous Meshing for CFD Modelling of Counter Flow Heat Exchanger." Journal of Advanced Research in Numerical Heat Transfer 5, no. 1 (2021): 26-34.

[15] Gao, Michael C., Pan Gao, Jeffrey A. Hawk, Lizhi Ouyang, David E. Alman, and Mike Widom. "Computational modeling of high-entropy alloys: Structures, thermodynamics and elasticity." Journal of Materials Research 32, no. 19 (2017): 3627-3641. https://doi.org/10.1557/imr.2017.366

[16] McCormick, Anthony, Eric Hultgren, Martin Lichtman, Jadon Smith, Ryan Sneed, and Shaun Azimi. "Design, Optimization, and Launch of a 3" Diameter N2O/Aluminized Paraffin Rocket." In 41st AIAA/ASME/SAE/ASEE Joint 
Propulsion Conference \& Exhibit, p. 4095. 2005. https://doi.org/10.2514/6.2005-4095

[17] El-Okda, Yasser M., and Ghassan Nasif. "Conjugate Effect on the Heat Transfer Coefficient." Journal of Advanced Research in Numerical Heat Transfer 5, no. 1 (2021): 1-8.

[18] Madhusudhan, Nivedha Karigiri, and Gerald Micklow. "Numerical and Thermochemical Analysis of Hybrid Rocket Fuels with Metallic Additives." Journal of Multidisciplinary Engineering Science and Technology 7, no. 11 (2020): 13074-13088.

[19] Baldissera, Rafaela, Victor LB Khün, Francisco Telöken, Juliano Carteri, and Matheus Poletto. "Evaluation of use waste aluminum on the burning of solid rocket propellant." Int. J. Adv. Sci. Tech. Res. 6, no. 9 (2019): 1-6. https://doi.org/10.26808/rs.st.i9v6.01

[20] Hashim, Syed A., Sanket M. Kangle, Srinibas Karmakar, and Arnab Roy. "Screening of nano-aluminum based solid fuels for hybrid rocket applications." In 2018 AIAA Aerospace Sciences Meeting, p. 0669.2018. https://doi.org/10.2514/6.2018-0669

[21] Lee, Changjin. "Combustion performance with ap and boron addition in staged hybrid rocket." In Journal of Physics: Conference Series, vol. 1721, no. 1, p. 012008. IOP Publishing, 2021. https://doi.org/10.1088/1742$6596 / 1721 / 1 / 012008$

[22] Carmicino, C., and A. Russo Sorge. "Experimental investigation into the effect of solid-fuel additives on hybrid rocket performance." Journal of Propulsion and Power 31, no. 2 (2015): 699-713. https://doi.org/10.2514/1.B35383

[23] Chen, Suhang, Yue Tang, Wei Zhang, Ruiqi Shen, Hongsheng Yu, Yinghua Ye, and Luigi T. DeLuca. "Innovative methods to enhance the combustion properties of solid fuels for hybrid rocket propulsion." Aerospace 6, no. 4 (2019): 47. https://doi.org/10.3390/aerospace6040047

[24] Li, Xintian, Hui Tian, Nanjia Yu, and Guobiao Cai. "Experimental investigation of fuel regression rate in a HTPB based lab-scale hybrid rocket motor." Acta Astronautica 105, no. 1 (2014): 95-100. https://doi.org/10.1016/i.actaastro.2014.08.028

[25] Chen, Suhang, Yue Tang, Hongsheng Yu, Xinyan Guan, Luigi T. DeLuca, Wei Zhang, Ruiqi Shen, and Yinghua Ye. "Combustion enhancement of hydroxyl-terminated polybutadiene by doping multiwall carbon nanotubes." Carbon 144 (2019): 472-480. https://doi.org/10.1016/i.carbon.2018.12.063

[26] Risha, Grant Alexander. "Enhancement of hybrid rocket combustion performance using nano-sized energetic particles." PhD diss., The Pennsylvania State University, 2003.

[27] Maggi, Filippo, Gabriela Gariani, Luciano Galfetti, and Luigi T. DeLuca. "Theoretical analysis of hydrides in solid and hybrid rocket propulsion." international journal of hydrogen energy 37, no. 2 (2012): 1760-1769. https://doi.org/10.1016/j.ijhydene.2011.10.018

[28] DeLuca, Luigi, Luca Rossettini, Charles Kappenstein, and Volker Weiser. "Ballistic characterization of AlH3-based propellants for solid and hybrid rocket propulsion." In 45th AIAA/ASME/SAE/ASEE joint propulsion conference \& exhibit, p. 4874. 2009. https://doi.org/10.2514/6.2009-4874

[29] Wu, Shi-kai, Ye Pan, Ning Wang, Tao Lu, and Wei-ji Dai. "Azo dye degradation behavior of AlFeMnTiM (M= Cr, Co, $\mathrm{Ni}$ ) high-entropy alloys." International Journal of Minerals, Metallurgy, and Materials 26, no. 1 (2019): $124-132$. https://doi.org/10.1007/s12613-019-1716-x

[30] Batchelor, Thomas AA, Jack K. Pedersen, Simon H. Winther, Ivano E. Castelli, Karsten W. Jacobsen, and Jan Rossmeisl. "High-entropy alloys as a discovery platform for electrocatalysis." Joule 3, no. 3 (2019): 834-845. https://doi.org/10.1016/i.joule.2018.12.015

[31] Lv, Z. Y., X. J. Liu, B. Jia, H. Wang, Y. Wu, and Z. P. Lu. "Development of a novel high-entropy alloy with eminent efficiency of degrading azo dye solutions." Scientific reports 6, no. 1 (2016): $1-11$. https://doi.org/10.1038/srep34213

[32] Yadav, Narendra, Prem Kumar Srivastava, and Mohan Varma. "Recent advances in catalytic combustion of APbased composite solid propellants." Defence Technology 17, no. 3 (2021): 1013-1031. https://doi.org/10.1016/i.dt.2020.06.007 